\title{
ForJando NUESTRAS DEMOCRACIAS. ENTRE RICHARD RORTY Y VLADIMIRO MONTESINOS
}

\author{
Miguel Giusti \\ Professor da Facultad de Filosofia \\ da la Pontificia Universidad Católica del Perú \\ E-mail: mgiusti@pucp.edu.pe
}

\section{Resumen}

El artículo busca explicar la historia reciente del Perú, en un ejercicio mediante el que es posible extraer ejemplos sobre el modo como han venido siendo (o no) forjadas las democracias latinoamericanas. El texto traza un paralelo entre las ideas desarrolladas por Richard Rorty en el libro recién publicado "Forjar nuestro país. El pensamiento de izquierdas en los Estados Unidos del siglo XX", y los sucesos del Perú de Fujimori y montesinos. Si, según cree Rorty, "el orgullo nacional es para los países lo que es la autoestima es para los individuos..." (1999, p.19), ¿cómo sería posible narrar una historia en la que aparecen pocos motivos de los cuales uno se pueda enorgullecerse? Buscando huir del fatalismo y del sarcasmo, el texto intenta demostrar que el trayecto político de Montesinos es, simbólicamente, un resumen del proceso de descomposición de la democracia peruana. En segundo lugar, analiza los movimientos de la izquierda política y habla del apoyo que el régimen recibió dentro y fuera del país, apoyo este que, en gran parte se basó en la ilusión de la estabilidad política. Por fin, afirma, tal como lo hace Rorty, que para forjar democracias es necesario que nos involucremos en defensa del Estado de Derecho.

Palabras claves: democracia; regime político peruano; Fujimori.

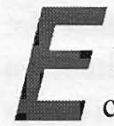

1 reciente libro de Richard Rorty, Forjar nuestro país (1999), comienza, como recordarán, con la siguiente reflexión: "El orgullo nacional es para los países lo que la autoestima para los individuos... Un exceso de orgullo nacional puede generar belicosidad e imperialismo, igual que demasiada autoestima puede producir arrogancia. Y, a la inversa, así como la carencia de autoestima le hace difícil a una persona demostrar entereza moral, un insuficiente orgullo nacional no favorece 
el debate enérgico y eficaz sobre la política nacional". Leí estas líneas hace unos meses, mientras presenciaba atónito cómo se iba desencadenando sin tregua y sin pausa la crisis política del Perú, y esas líneas, como las que le siguen en el libro, fueron inscribiéndose en un contexto distinto al del original. La vida y la tradición políticas de la nación peruana, no principalmente las de la norteamericana, ocuparon poco a poco el foco de mi atención. Leí las reflexiones de Rorty sobre la forma de narrar nuestras historias políticas nacionales y sobre la artificialidad de los debates de la izquierda política y la izquierda filosófica, permanentemente solicitado por los anuncios alarmantes de la vida política cotidiana en el Perú y por el creciente clima de inestabilidad que reinaba y reina aún a mi alrededor. Por eso, cuando recibí la invitación a participar en este Simposio, pensé que le daría yo mismo la razón a Rorty, es decir, que caería yo mismo en las trampas de la izquierda filosófica culturalista, si optaba, como se me ocurrió en un primer momento, por preparar una conferencia sobre un tema académico de cuello y corbata como conviene para estas ocasiones. No podía en realidad dejar de hablar de lo que saltaba políticamente a la vista con tanta evidencia. Pensé entonces que podía usar el texto de Rorty, que considero una contribución muy sugerente para la filosofía política actual, como telón de fondo de una reflexión un tanto libre sobre las lecciones que puede dejarnos la reciente evolución política del Perú.

Eso sí, a diferencia de Rorty, que escribe ese libro animado por un inocultable orgullo nacional, los comentarios que yo les voy a transmitir están animados por un sentimiento casi opuesto, un sentimiento de vergüenza por lo que pasa en mi país. La autoestima de los peruanos está hoy efectivamente por los suelos. Por eso nos pasa, como también dice Rorty sobre ciertos intelectuales de su país, que cuando queremos relatar nuestra historia nos asalta con frecuencia una doble tentación: la del fatalismo o la del sarcasmo' ${ }^{\prime}$ O describimos nuestra situación como el eterno retorno de males que nos son endémicos, o nos burlamos de ella como de un espectáculo hilarante. Hacemos de esa historia un lamento o una opereta. Eso, dice Rorty, es precisamente lo que

1 Rorty habla de "selfmockery" y de "selfdisgust". Del Castillo traduce esas expresiones como "burla" y "malestar". Creo que "fatalismo" y "sarcasmo" son palabras más expresivas. 
ocurre cuando la verguienza es mayor que el orgullo, en las personas y en los países. Y por lo mismo advierte que nuestra reflexión política sólo podrá ser imaginativa, o constructiva, si nuestro orgullo se sobrepone a la vergüenza. Como creo que tiene en el fondo razón, trataré por mi parte de hacer este ejercicio y de ofrecerles una lectura comprensible de la historia reciente del Perú, es decir, una lectura de la que puedan extraese lecciones sobre el modo en que se están forjando, o dejando de forjar, nuestras democracias latinoamericanas.

Voy a tomar del texto de Rorty dos ideas centrales, que me van a servir para ordenar los hechos y las explicaciones que componen esta historia. La primera idea ha sido ya aludida: se refiere a la necesidad de resistir a la tentación del fatalismo o el sarcasmo, y de narrar una historia que sobreponga el orgullo a la vergüenza nacional. Sostendré, en esta primera parte, que la complejidad de la evolución política del Perú puede resumirse simbólicamente en la historia de Vladimiro Montesinos, lo cual no es naturalmente motivo alguno de orgullo, pero sí un modo de nombrar, y acaso hasta de explicar, el proceso de descomposición de nuestra-democracia. La segunda idea es la de los fantasmas distorsionantes de la izquierda política. Piensa Rorty que esta izquierda se ha enfrentando artificialmente, durante décadas, a la más genuina tradición liberal, confundiendo cosas esenciales, ignorando alianzas de fondo y haciéndole finalmente el juego a la derecha. Aprovecharé esta reflexión para referirme a la confusión de las posiciones políticas frente al gobierno de Fujimori, y para explicar las causas del amplio respaldo que este régimen obtuvo durante años, dentro y fuera del Perú. Hablaré aquí sobre la ilusión de estabilidad que el régimen suscitó, respaldado por la expresa o implícita complicidad de muchas tendencias políticas. A esta idea se vincula la crítica que hace Rorty de la tendencia "culturalista" de las izquierdas. Se refiere con esta expresión al giro dado por la nueva intelectualidad filosófica al concentrarse en "estudios de victimismo" , es decir, en estudios sobre la reinvidación de identidades humilladas, pues ello la ha llevado a desentenderse de la agenda política concreta de su país. Una cosa análoga podría decirse, mutatis

2 La expresión "estudios de victimismo" la toma Rorty de Stefan Collini. Cf. Rorty, R., p. 74. 
mutandis, sobre lo ocurrido con la izquierda y los partidos políticos en el Perú, que, cuando no han sido víctimas del fatalismo o del sarcasmo, se han desentendido de los problemas de la agenda política nacional. Terminaré mi conferencia con una conclusión que se acerca a la de Rorty en sus propósitos, aunque no en su fundamentación. Sostendré que, para forjar nuestras democracias, debemos comprometernos más resueltamente en la defensa del estado de derecho de nuestras sociedades, pero no, como sugiere Rorty, porque ése sea un ideal que late en nuestras tradiciones, sino más bien por lo contrario: para contrarrestar la tendencia clientelista y antidemocrática que nos acecha permanentemente y que, en el caso reciente del Perú, se puso de manifiesto con claridad a través de la vida y milagros del señor Vladimiro Lenín Montesinos Torres.

El ejercicio que les propongo no es artificial, ni tampoco puramente localista. Voy a relatar, por supuesto, una historia particular, pero que se emparenta, me parece, con otros procesos que viven las democracias latinoamericanas y, lo que es más importante, que se inscribe en el marco de una sintomática evolución de la filosofía política contemporánea y de sus consecuencias prácticas. Porque, por más norteamericana que pretenda ser, la obra de Rorty se refiere a un clima cultural relativo a la política que nos contagia a todos, aunque varíen las circunstancias o los síntomas. Las ideas que acabo de mencionar la tentación del fatalismo y el sarcasmo en el enjuiciamiento de nuestras historias nacionales, los fantasmas políticos de la izquierda y el giro hacia el culturalismo- son fenómenos, o epidemias, que circulan por el mundo entero y que plantean desafíos a la reflexión sobre el futuro de nuestras democracias.

\section{Sincera confesión: entre el fatalismo y el sarcasmo}

No es preciso advertir que de lo que aquí se trata no es de atribuir a un siniestro personaje la responsabilidad exclusiva de los males del Perú ni tampoco en sentido estricto de narrar su historia personal, pese a que ésta haría las delicias de cualquier psicoanalista. El nombre de Montesinos ha de aparecer más bien como una clave para 
entender los síntomas que aquejan a la democracia peruana, síntomas de los que él es una privilegiada expresión. Pero ya que he mencionado el asunto de su nombre y las reacciones de los psicoanalistas, entraré en materia recordando lo que un conocido psicoanalista peruano escribiera una vez sobre él. Vladimiro Montesinos, nos recuerda Bruce Jorge, es uno de los tres peruanos que han pasado a nuestro imaginario colectivo en las últimas décadas por su nombre de pila. No por su apellido, como tantos otros, sino por su solo nombre, que al ser pronunciado despierta emocionales, violentas reacciones. Esos tres peruanos, esos tres nombres son: Alan, Abimael y Vladimiro. Alan García, Abimael Guzmán y, justamente, Vladimiro Montesinos. Pues bien, sobre la base de esta constatación, el psicoanalista nos cuenta que en sus visitas al manicomio de Lima, solía someter a sus pacientes a la prueba de ver cómo reaccionaban al oir alguno de esos nombres, con el propósito de averiguar así si contaban aún con algún principio de realidad.

El principio de realidad de los peruanos pasa efectivamente por reconocer la trágica relación que existe entre esos tres nombres propios. "Alan" representa el fracaso histórico de los partidos políticos de la izquierda democrática, un fracaso que se añadía al de toda la clase política tradicional, precisamente en momentos en que "Abimael" y su ejército luminoso estaban librando una cruenta guerra interna que dejaba graves secuelas de desintegración social e inestabilidad política. Fue en ese terreno que floreció el proyecto autoritario de Alberto Fujimori. Su imagen política se asoció rápidamente a la figura del eficiente componedor de la situación económica y de la pacificación política, al enérgico garante de la estabilidad social en un país convulsionado. Pero, lo que no se vio a primera vista, fue que este proyecto sólo pudo sostenerse gracias al poderosísimo sistema de extorsión política implementado en la sombra por el tercero de aquellos nombres propios, por el conspirador "Vladimiro".

No puedo dejar de mencionar en este contexto un comentario que hace Rorty al final de su libro sobre el peligro principal que, en su opinión, acecha hoy en día a las viejas democracias de los países industrializados. Éstas estarían entrando, nos dice, en un "nuevo Período de Weimar", es decir, en una fase propicia para el surgimiento de movimientos fascistas o populistas. No estando ya el sistema en condiciones de satisfacer las grandes demandas sociales ni de impedir 
la transnacionalización del empleo y los capitales, el electorado de esos países puede sentirse tentado a buscar a "un hombre de hierro" que prometa reordenar las cosas, aun cuando, como es sabido, las soluciones de los problemas de Weimar suelan conducir a tragedias peores. Rorty cita en su apoyo a estudiosos de la economia política, y menciona expresamente la tesis de Edward Luttwak sobre la amenaza de fascismo que se cierne sobre el gran sueño americano. Semejante peligro no es sin embargo exclusivo de aquellas viejas democracias industrializadas, sino lo es igualmente, como lo estamos viendo por los casos del Perú y de Venezuela, y como se hace sentir cada vez más fuertemente en Colombia, para las precarias democracias latinoamericanas. Sería seguramente inadecuado decir que éstas últimas estén viviendo un periodo de Weimar, pero no que es sobre todo en ellas donde el autoritarismo se ofrece como una ilusión populista ante un electorado defraudado por la incapacidad de las instituciones políticas para resolver sus graves problemas económicos y sociales.

Vuelvo a la historia de los nombres propios y del proyecto autoritario del Perú. Vladimiro Montesinos conoció a Alberto Fujimori cuando éste acababa de sorprender a la opinión pública disputándole la victoria a Mario Vargas Llosa en la primera vuelta de las elecciones generales de 1990. Fue Montesinos quien se presentó ante el entonces desconocido pero ya prometedor candidato para ofrecerle sus servicios. A su primera entrevista llevaba un valioso material de interceptación telefónica del equipo de campaña del candidato opositor, obtenido gracias a sus contactos en el Servicio de Inteligencia. Y, si debemos dar crédito a las declaraciones del hermano de Pablo Escobar, pues le habría llevado también una generosa contribución para financiar su campaña en la segunda vuelta. Fujimori se interesó de inmediato en el furtivo abogado, a quien desde entonces retuvo a su lado, y le encargó muy pronto otro servicio: sanear legalmente, es decir: adulterar, los documentos de sus pequeñas transacciones agrícolas e inmobiliarias, pues se había filtrado a la prensa que en ellas había cometido flagrantes irregularidades. Así comenzó el funesto pacto entre estos dos personajes: ambos pensaron que podrían aprovecharse uno del otro, ambos parecían necesitar exactamente lo que el otro poseía: Fujimori, un asesor inescrupuloso que le hiciese el trabajo sucio en la sombra; 
Montesinos, una autoridad legítima que le permitiese ejercer a sus anchas el poder de la conspiración.

El primer gran servicio que llevó a cabo el asesor, apenas Fujimori ganó las elecciones, fue hacer una purga entre los altos mandos de las Fuerzas Armadas para asegurarle al presidente un respaldo incondicional de aquella institución y para comprometer de paso también a los militares en el proyecto autoritario. Fujimori había llegado al poder sin partido político ni bases institucionales, no tenía mayoría en el Congreso y era un perfecto desconocido en el mundo de la economía y la política internacionales. Su posición política interna era muy débil, pese a su exótico carisma de japonecito cholo y a su aura de administrador austero. La alianza con los militares, interesados por su parte en instaurar un gobierno fuerte que pusiese orden en el país y contribuyese a afrontar más resueltamente a la subversión, le otorgó a Fujimori el respaldo institucional del que carecía por las razones mencionadas. Lo relevante de esta alianza, por sí sola quizás políticamente comprensible, fue el método. Montesinos, él mismo capitán retirado del Ejército, intervino directamente desde entonces, con la anuencia del presidente, en la remoción y el nombramiento de las autoridades militares, en los pases al retiro, en la decisión de los ascensos, en la distribución de los cargos internos de las FFAA, ofreciendo en todos los casos compensaciones financieras a los militares favorecidos y extorsionando a los que tuvieran dudas o vacilaciones. El tejido mafioso que empezó a urdirse ya en los inicios del régimen de Fujimori es tan impresionante y, sobre todo, tan grosero, que casi no parece verosímil. El que no lo parezca ha sido precisamente una de las causas de su sorprendente estabilidad a lo largo de los años, como veremos en el segundo punto. Pero ahora, que está apenas empezando a destaparse la olla podrida, ha llegado a saberse que, sólo en lo que respecta a los militares, se había organizado todo un sistema jerárquico de prebendas que incluía pagos regulares de miles de dólares a los oficiales dependiendo de su rango y del grado de su sumisión política. El método de la extorsión tenía su complemento en la complicidad de los involucrados al aceptar compensaciones financieras. Y tenía además su corolario en la patológica compulsión de Montesinos por registrar en videos todos los sobornos que él se deleitaba en entregar de su propia mano para tener así luego un recurso 
privilegiado de chantaje. Una vez echado a andar este sistema, ya no era posible dar marcha atrás. Se introdujo así una cuña perversa de desestructuración de la institución del ejército.

Luego del Ejército vino el Congreso. Como todos recuerdan, Fujimori dio un autogolpe y disolvió el Congreso en 1992, dos años después de haber sido elegido presidente. Lo pudo hacer gracias a que ya contaba con el respaldo de las Fuerzas Armadas. Y el momento fue políticamente oportuno para los intereses del proyecto autoritario porque por su precaria representación parlamentaria el presidente tenía las manos atadas para implementar sus reformas, y la violencia terrorista se hallaba en su punto más álgido. Efectivamente, la gran mayoría de la población celebró esa medida, confiada en la honestidad del hombre de hierro y convencida de la necesidad de poner drásticamente fin al desorden social. Los acontecimientos posteriores parecieron además darle la razón al presidente pues pocos meses después se capturó al cabecilla de Sendero Luminoso, a "Abimael", y se produjo entonces el milagro de la pacificación polìtica que tantos réditos le diera al gobierno de Fujimori. El caso es que en la cúspide de su éxito político, el presidente convocó a un Congreso Constituyente, en el que obtuvo la mayoría absoluta, como la obtendría luego en todas las otras convocatorias a elecciones parlamentarias. Pero lo insólito fue nuevamente el método político empleado. Con la valiosa ayuda de su asesor, Fujimori elaboró siempre personalmente las listas de candidatos de su agrupación, reclutados entre profesionales y ciudadanos independientes convencidos quizás del buen rumbo de las reformas pero dispuestos a acatar el sistema autoritario de decisiones políticas que les estaba dando legitimación. Y para que no quedaran dudas del propósito del régimen de impedir una continuidad partidaria institucional, Fujimori se dio el trabajo de crear (o, en algún caso, de inventar fraudulentamente) tres diferentes partidos políticos, uno para cada elección, para que nadie tuviera pretensiones de protagonismo político, para cultivar de modo perverso la lealtad al caudillo, y para que la rivalidad entre sus partidarios tuviera el efecto de reforzar su autoridad. El modo en que ha funcionado el Congreso del Perú en los últimos ocho años es realmente para una antología de la vergüenza: los parlamentarios eran llamados periódicamente a Palacio para recibir 
instrucciones sobre lo que debían discutir y lo que debían votar, y cuándo, y cómo. El Ejecutivo se tomó todas las licencias que quiso para darse atribuciones legislativas, teniendo al Congreso como comparsa. Y, lo que es más humillante aún, encargó al Parlamento la aprobación de leyes anticonstitucionales y le hizo revertir decisiones que antes le había ordenado tomar, la más grotesca de las cuales fue la destinada a permitir la así llamada "re-reelección". La institución del Congreso perdió su sentido específico como poder del Estado y se amoldó al sistema autoritario y extorsionador del régimen.

Al poder legislativo siguió el poder judicial. Todo el sistema de administración de justicia del Perú se hallaba en aquel entonces en una severa crisis, no sólo debido a los habituales problemas de nuestra idiosincracia, sino sobre todo debido a las secuelas de corrupción e intimidación generadas por el terrorismo y el narcotráfico. Era urgente una reforma del poder judicial, era urgente y era reclamada por todos, dentro y fuera del país. La coyuntura fue pues sumamente propicia para que el astuto asesor pusiese en obra todo su talento y montara una de las más ingeniosas y perversas redes de extorsión del sistema judicial, la que llegaría a ser el arma más eficaz del proyecto autoritario, y para que lo hiciera por añadidura con fondos del Banco Mundial y de la comunidad internacional. Aparentando querer implementar un complejo proceso de reformas para el largo plazo, el gobierno ejecutó en lo inmediato un plan de intervención del poder judicial consistente en entregar la administración de la justicia a una serie de salas llamadas "transitorias" y a un conjunto de jueces y fiscales llamados "provisionales", nombrados por el propio Ministerio Público, mantenidos en sus cargos por medio del soborno o del chantaje, y a condición naturalmente de que procedieran de acuerdo con las instrucciones del régimen. Con esa maquinaria en marcha se puso freno, en primer lugar, a cualquier recurso judicial en contra de las decisiones o las medidas del gobierno, y, en segundo lugar, se tuvo el camino despejado para aplicar mecanismos de extorsión a fin de doblegar la voluntad de las instituciones y las asociaciones de la sociedad civil que no estuvieran alineadas con el gobierno, y a fin de amedrentar al conjunto de la población. Teniendo en sus manos las riendas del poder judicial, el gobierno pasó de la retaguardia a la ofensiva. 
La prensa fue la primera víctima de ese andamiaje ahora sí ya francamente gangsteril. El gobierno - 0 , más exactamente, Montesinos desde sus oficinas en el fatídico Servicio de Inteligencia Nacional (SIN)hizo abrir procesos judiciales en contra de los canales de televisión o de los diarios, ya sea desempolvando viejas querellas o inventando nuevas, para obligarlos a silenciar información, a despedir periodistas, a cerrar programas, en una palabra, para obligarlos a someterse a la censura del régimen bajo la amenaza de condenas judiciales que podrían costarles, y que en más de un caso efectivamente les costaron, la propiedad misma de sus medios de información. Como Montesinos era además particularmente diestro en lo que llamaba "operativos psicosociales", en decir, en campañas masivas de desinformación dirigidas a provocar reacciones distorsionadas en la opinión pública, pues montó paralelamente una poderosa empresa de periódicos amarillos distribuida casi gratuitamente en todos los rincones del país, con el objeto de alimentar a la población con las noticias y los rumores que deseaba el gobierno, entre los cuales estaba por cierto el ataque frontal a los líderes de la oposición. A cargo de esta gigantesca empresa estuvo un gangster argentino, de apellido Faisal, que acaba de fugar del Perú, justo cuando estaba por llegarle la primera requisitoria judicial.

La crónica es larga y las ramas de la corrupción son bastante más frondosas de lo reseñado aquí. Habiendo copado todos los poderes del Estado, incluyendo a la prensa y la televisión, teniendo a las Fuerzas Armadas perfectamente alineadas, y habiendo convertido a cientos de funcionarios y empresarios en cómplices del sistema, la maquinaria extorsionadora se desplegó a su antojo, afectando por igual la vida de los municipios, las universidades, los gobiernos regionales, las empresas, los colegios profesionales y tantas otras instituciones de la sociedad civil que fueron desarticuladas en su estructura interna y pervertidas en su función misma. Se llegó al punto aquél en la vida de las dictaduras en que la sociedad en su conjunto es psicológicamente doblegada, de modo que ya no es posible distinguir la línea que separa a la complicidad del temor. Por eso justamente dice Mario Vargas Llosa que el gobierno de Fujimori le ha dejado al Perú "una herencia maldita". Y para que no quepan dudas sobre la verdadera naturaleza del régimen, han venido ahora a destaparse los negocios de Montesinos con el 
narcotráfico y con el comercio internacional de armas, especialmente en relación con la guerrilla colombiana, y muchas cuentas millonarias de más que dudosa proveniencia.

Felizmente, habría quizás que decir, por su lógica misma el sistema se fue volviendo inmanejable. La de Fujimori ha sido, para utilizar términos de los cientistas políticos, una dictadura "personalizada", no una "institucional". Todo ese inmenso poder estuvo concentrado en manos de Montesinos y Fujimori, no en manos de la institución de las Fuerzas Armadas ni en las de un partido o un movimiento. Todos los hilos, cada vez más complejos, de una maquinaria que abarcaba cada vez a más gente y que demandaba una red cada vez mayor de extorsión, eran dirigidos sólo por estos dos hermanos siameses, o, mejor dicho aún, pasaron paulatinamente a ser dirigidos sobre todo por Vladimiro Montesinos, que era precisamente quien tenía por misión hacer el trabajo sucio... lo que ahora venía a ser ya casi todo el trabajo. Para contrarrestar la creciente indignación de muchos sectores, la insatisfacción de la población por el deterioro de la situación económica y la protesta ciudadana en las calles, el sistema sólo parecía poder actuar ramificándose aún más y recurriendo a medidas de chantaje aún más burdas. La olla podrida reventó hace unas semanas cuando se dio a conocer el video en que se veía y oía a Vladimiro Montesinos comprando a un congresista de la oposición para que se pasara a las filas del gobierno. Con razón se ha llamado a ese documento "el video de la vergüienza". A partir de ese momento, la historia comenzó, también indetenible, su cuenta regresiva. La imagen del presidente Fujimori tratando de aparentar inocencia y muerto de miedo por las revelaciones que podría hacer su hermano siamés, se ha vuelto francamente patética.

Pero, ¿es ésta acaso una crónica de la maldad? ¿Estamos ante la historia de un personaje siniestro que por su sola e inicua astucia logró torcer la voluntad y las mentes de millones de peruanos? Desgraciadamente no es así. Desgraciadamente. Porque, si así fuese, bastaría con deshacernos de él para recomponer nuestra democracia. El éxito de Vladimiro Montesinos y de Alberto Fujimoni sólo pueden entenderse, en realidad, como la expresión epidérmica de muchos males que aquejan a la sociedad peruana y que la hacen vulnerable a la corrupción, al clientelismo, al caudillismo, a las prácticas 
antidemocráticas. Para que el sistema de extorsión pudiese funcionar, debía haber una sociedad dispuesta a dejarse extorsionar; para chantajear a la clase política, para destruir la institucionalidad de las Fuerzas Armadas o para comprar jueces a cambio de sobornos, era preciso que todos estos personajes, al menos en cierta medida, se prestaran al juego. Pero, por sobre todo, debía haber una sociedad políticamente enceguecida que creyese en las bondades del proyecto autoritario de Fujimori, y que se mostrase dispuesta a pasar por alto maniobras cada vez más escandalosas con la ilusión de que todo ello era el costo de nuestra estabilidad económica y política. Sobre ello hablaré enseguida. Lo que debe habernos quedado claro, en todo caso, es que Fujimori y Montesinos han sido las dos caras de una misma moneda: la apariencia de estabilidad representada por el primero tenía su crudo correlato en la maquinaria gangsteril del segundo. No se entienden el uno sin el otro: Montesinos es la verdad de Fujimori.

\section{Las locas ilusiones sobre la estabilidad del país}

La historia que acabo de relatar es una historia vergonzosa. Tratar de explicarla nos obliga, como dijimos al comienzo, a no ceder a la tentación del fatalismo o el sarcasmo, pues ambas tentaciones sólo ponen de manifiesto de diferentes formas una misma actitud de resignación frente a la realidad, que es un síntoma más de la falta de autoestima nacional. Algo así le ha ocurrido, piensa Rorty, a la izquierda política de los Estados Unidos: que se ha desentendido de la agenda política real por haber ontologizado en cierto modo los males de su sociedad, y por no haber comprendido quiénes podrían haber sido sus verdaderos aliados en la construcción de una sociedad más solidariamente democrática. En el caso del Perú, lo que podría decirse es que muchas fuerzas políticas y sociales se confabularon involuntariamente para hacer posible aquella historia vergonzosa. Todas ellas fueron, aunque no todas simultáneamente, víctimas de una ilusión sobre los beneficios que habría de traer para el país la realización de un proyecto autoritario. Y muchas de ellas creyeron en su momento que los costos del autoritarismo eran menores que los beneficios de la estabilidad. 
Grave error de percepción, y de cálculo, políticos, por los que nuestra sociedad tiene hoy que pagar un precio muy alto. Si tratamos de presentar a continuación algunos de estos malentendidos políticos, podremos quizás al final extraer conclusiones aleccionadoras.

Recordemos, en primer lugar, que Fujimori llegó al poder en 1990 con el casi pleno respaldo de los movimientos de la izquierda democrática. Un conocido analista político de izquierda de aquel entonces, hoy adversario acérrimo del gobierno, publicó en plena campaña electoral un artículo al que puso por título, evocando la película de Alain Resnais: "Fujimori, mon amour". Es una definición perfecta de lo que fue la actitud de la izquierda ante el triunfo político de Fujimori. La izquierda celebró con entusiasmo la derrota de la ancha alianza conservadora congrregada en torno a Mario Vargas Llosa, y celebró igualmente entusiasta el ascenso al poder de un hombre del pueblo que había sido víctima de una doble marginación pues pertenecía a una minoría racial perseguida en el Perú. Percibió, por así decir, el significado cultural del triunfo de Fujimori, pero no tuvo ojos para ver que aquella alianza derrotada se sostenía en realidad (o al menos en principio) sobre un proyecto democrático y liberal, ni, mucho menos, tuvo olfato para sospechar lo que podía traer consigo el gobierno de un independiente desligado por completo de los partidos y de las instituciones de la sociedad civil. Le ofreció por eso al candidato apoyo ideológico en la preparación de su plan de gobierno, y participó activamente en los primeros gabinetes ministeriales del nuevo régimen ocupando altos cargos. Confió quizás en la posibilidad de construir una inédita alianza popular y socializante que cerrase el paso a la implementación del modelo neoliberal, y no se interesó mayormente por los manejos que Fujimori y su asesor comenzaban ya entonces a urdir en la sombra. Porque, lo que era claro para ellos, como lo sería luego para todos los colaboradores del régimen, era que su participación y la eventualidad de su influencia en la política del país dependían exclusivamente de la voluntad y de la confianza del presidente, único beneficiario del respaldo popular y único detentor del poder, que podía nombrarlos y cambiarlos sin rendir cuentas ante nadie. Su error consistió precisamente en depositar su confianza en un político de esta naturaleza y en contribuir así indirectamente a su legitimación. 
Pero el entusiasmo de la izquierda por Fujimori fue sólo circunstancial y pasajero. Mucho más orgánico y duradero, por consiguiente mucho más comprometedor, fue el apoyo que le dio aquella derecha derrotada en las elecciones. Porque, pragmático como era, Fujimori entendió pronto que la opción política que más se ajustaba a su proyecto autoritario de recomposición del país era buscar la reinserción inmediata de nuestra economía en el sistema financiero internacional, y con ese fin se mostró dispuesto a jugar el papel de administrador eficiente de las reformas estructurales que dictaran el Fondo Monetario y otros organismos financieros. Para éstos, el país requería de una urgente terapia de ajuste fiscal y de un plan inmediato de modernización de la economía en su conjunto. Fujimori cumplió su tarea a cabalidad, y se deshizo por eso rápidamente de sus ocasionales aliados izquierdistas. Fue entonces la derecha la que reaccionó con estusiasmo, y la que celebró emocionada la conversión de Frnimori. Como por arte de magia resultaba que su propio programa económico, que le había costado las elecciones, empezaba a ser ejecutado, y de forma aún más drástica, por el artífice de su derrota. En pocos meses llegó dinero fresco al Perú, se implementó una reforma neoliberal de largo alcance, la economía se puso en marcha. Fujimori pasó a ser el gran ordenador y administrador del cambio. Cualquier otra situación dudosa en el plano de las libertades democráticas parecía ser secundaria.

Mario Vargas Llosa suele protestar enérgicamente cuando oye decir, cosa muy frecuente, que Fujimori aplicó el programa de gobierno de su movimiento político, el Frente Democrático. El argumento que emplea para justificar su protesta es que el programa económico de su movimiento, al que se suele hacer alusión, se asentaba sobre un proyecto político de inspiración democrática que había sido pensado además como un gran proyecto nacional. Aunque este argumento es probablemente más válido para él que para muchos de sus acompañantes de aquel entonces, lo cierto es que en términos ideales tiene toda la razón. El frente de partidos y agrupaciones empresariales que respaldó su candidatura se desintegró políticamente con la derrota electoral. Y cuando brindó su apoyo a Fujimori, lo hizo confiando exclusivamente en los efectos benéficos que tendría para el país el reordenamiento de su economía, renunciando implícita o explícitamente 
a su capacidad de diálogo político con el gobierno. La derecha no elaboró ninguna propuesta política orgánica que diese marco a las reformas económicas, dejó esa tarea en manos del gobierno (es decir, de Fujimori y Montesinos) y se desentendió por eso de los malos manejos y de los abusos de poder que cundían por doquier. Es más, en su caso la legitimación del autoritarismo no fue sólo indirecta; la ausencia de la democracia fue conscientemente tolerada como el precio que debía pagarse por la modernización en un país desintegrado y desarticulado como el nuestro. Sólo tardíamente, cuando la red de extorsión del poder judicial llegó a tocar sus propios intereses, o cuando la obcecación de Fujimori por perpetuarse en el poder condujo a desestabilizar la situación económica, recién entonces la derecha empezó a percatarse de su error. Había percibido, por así decir, las ventajas de la estabilidad económica, pero no había tenido ojos ni oídos para captar los efectos contraproducentes que el autoritarismo habría de tener sobre aquella misma, ilusoria estabilidad económica.

La primavera política del fujimorismo llegó, sin embargo, con la captura de Abimael Guzmán. En ese momento ya no fue la izquierda política ni la derecha económica, sino la población en general la que cerró filas tras el presidente, avalando manifiestamente el autoritarismo por los efectos que había llegado a producir. La paz justificaba casi cualquier medio. Esa reacción de la gran mayoría silenciosa de la población ha sido sin duda la principal y la más prolongada fuente de legitimación del gobierno dictatorial. Habría que haber vivido la dolorosa agonía de la sociedad peruana en los últimos cuarenta años, o haber sufrido la sucesión de plagas que la azotaron -como los ciclos de fracasos económicos, la corrupción política, las migraciones forzadas, el abandono del campo, el incremento de la pobreza y, por sobre todo, la sangrienta guerra interna que dejó al país sin industrias, sin bienes, sin carreteras, sin energía, sin agua y con muertos regados por calles y plazas-, habría que haber vivido todo eso, decía, para entender por qué la población peruana le firmó un cheque en blanco a Alberto Fujimori durante tanto tiempo. La posibilidad de vivir en paz fue considerada el bien más preciado, muy por encima de cualquier otra consideración relativa a la ausencia de maneras democráticas o al empleo de métodos supuestamente ilícitos. Si el hombre de hierro había logra- 
do poner orden en el país por esos métodos, pues ello debía significar que debían darse por bien habidos. Quien cuestionase la legitimidad del régimen por los métodos que empleaba, se hacía indirectamente cómplice del desorden y el terror al que el régimen acababa de poner fin. Para algo como esto tienen seguramente oídos los colombianos, y es por eso que suelen expresar el deseo de tener aquí a un Fujimori (Maturana!). Pero es bueno que oigan la historia completa para que no tengan que lamentar lo que nosotros ahora.

Este respaldo incondicional que Fujimori recibió de la población peruana por tanto tiempo tiene, a mi entender, una particular significación moral, sobre la que vale la pena llamar la atención pues hay en ella algo genuino y algo esquizofrénico a la vez. La derrota del terrorismo tuvo en el Perú un efecto psicológico-social espectacular, produjo una esperanzada movilización nacional, que bien puede considerarse moral porque fue una gran fuerza de motivación de toda una colectividad. Pero como en tantos otros países que han vivido guerras internas, no sólo en América Latina, esa voluntad moral colectiva no fue debidamente procesada, no logró articularse en un proyecto político de unidad nacional ni desembocó siquiera en un esfuerzo de comprensión de las causas que habían generado un terrorismo tan tardío. Fue tan solo una adhesión ciega al caudillo, a la eficacia de su programa y a sus métodos, sin llegar a percibir el efecto contraproducente que esa misma confianza habría de tener sobre la propia paz social. Con la lentitud de los movimientos morales colectivos, esa voluntad se ha ido desplazando con el tiempo, y, si antes fue el soporte más estable del fujimorismo, hoy se está expresando como una gran fuerza de indignación moral. Sacudida por las noticias que dan cuenta del insólito grado de corrupción del sistema autoritario, la mayoría silenciosa despierta de un prolongado letargo y expresa su protesta en calles y plazas. Nuevamente ha llegado a reunirse un potencial moral movilizador, que merece una mejor suerte.

Otro de los grandes soportes de legitimación del proyecto autoritario de Fuijimori y Montesinos ha sido la comunidad internacional, en particular los organismos del mundo financiero. Y también en este caso se trató de un grave error de percepción política. Que esto ocurriese con las entidades financieras, no debería llamar tanto la 
atención, porque en sus políticas suele primar un criterio pragmático acerca de las proyecciones de sus reformas en el aparato productivo de los países concernidos. Sucumbieron también ellas al espejismo de la estabilidad social que al parecer estaba siendo garantizada por el régimen, y consideraron como parte de nuestra idiosincracia el que para llegar a ese fin se tuviese que recurrir a métodos heterodoxos. Pero lo que sí ha llamado poderosamente la atención a los peruanos democráticos, es el respaldo que le fue otorgado al gobierno mafioso de Fujimori por muchos gobiernos latinoamericanos. El caso más patético de esta crónica miopía política ha sido la actitud contemporizadora de la Organización de Estados Americanos, especialmente en los momentos más difíciles de la historia peruana reciente, con la honrosa excepción del Embajador Eduardo Stein, Jefe de la Misión de Observación de la OEA en las elecciones presidenciales del pasado mes de abril, quien declaró valientemente que no era posible avalar un proceso tan fraudulento. Esa valiente declaración le costó en la práctida el retiro de la confianza del Secretario General y de los demás presidentes, que en aras de una supuesta estabilidad de la región se mostraron dispuestos a avalar un proceso eleccionario absolutamente irregular y un régimen ya completamente podrido. En más de una ocasión el señor César Gaviria ha jugado un papel decisivo para el mantenimiento del gobierno de Fujimori y Montesinos; en más de un caso su intervención política sirvió para debilitar los esfuerzos de la oposición democrática interna; y en lo que respecta a los acontecimientos de los últimos meses, su desempeño ha sido poco menos que hilarante. Al observarlo al lado de Fujimori, uno no sabía a ciencia cierta si Gaviria era un cómplice o simplemente un incauto más. Pero sea cual fuere la razón, el hecho es que ha sido su más útil aliado internacional. Los peruanos no olvidaremos el desconcierto ni la indignación que nos produjo ver al Secretario General de la OEA interceder con celeridad y celo desmedidos ante los demás presidentes latinoameicanos y ante la propia presidenta de Panamá para que se otorgara asilo político al más grande ladrón y al más poderoso extorsionador que ha conocido la historia del Perú. Felizmente la señora Mirella Moscoso actuó con inteligencia, con cautela y con olfato político, resistiéndose a admitir la lógica torcida 
de las alianzas entre los presidentes y haciendo prevalecer, en contra de los ruegos de Gaviria y de Cardoso, un límite de ética política por sobre las conveniencias estratégicas de la estabilidad.

\section{¿Solamente una vez?}

Este recuento de malentendidos políticos no ha sido, por supuesto, exhaustivo, como tampoco lo fue el recuento de los mecanismos de extorsión ni el de las instituciones sociales destruidas que hice en la primera parte. Lo que he presentado es sólo una selección de casos suficientemente representativos que sirvan para dar coherencia a la historia que estoy tratando de narrar. De un lado, hemos visto cómo se fue gestando un proyecto político autoritario por medio de la alianza mafiosa entre Vladimiro Montesinos y Alberto Fujimori. Paso a paso, con una lógica que llegó a hacerse incontrolable, fueron copando los poderes del Estado y destruyendo las instituciones de la sociedad civil. De otro lado, hemos tratado de hacer comprensible por qué ese proyecto autoritario pudo contar con un respaldo real, y por qué fue éste tan prolongado. Evocando la tesis de Rorty sobre la confusión política que contagia hoy en día a los movimientos progresistas, hemos interpretado el respaldo a Fujimori como una secuencia de posiciones políticas equívocas de parte de los diferentes actores de la vida social en el Perú. Casi todos ellos le dieron su apoyo al régimen, aunque no simultáneamente. $\mathrm{Y}$ lo hicieron siempre percibiendo un beneficio, no advirtiendo sus costos, o creyendo ser capaces de cargar con ellos. La izquierda lo ayudó a llegar al poder, confiando en la reivindicación cultural que su triunfo podía significar para las clases humilladas del país. La derecha lo apoyó durante años, entusiasmada por lo que parecía ser la implementación definitiva de la modernización económica. La población en general le firmó un cheque en blanco pensando que de esta forma aseguraba la pacificación de la sociedad. Y la comunidad internacional imaginó que todos esos factores anteriores eran reales, y confió por lo tanto en que Fujimori era un administrador eficiente y un interlocutor seguro respaldado por la gran mayoría de la población peruana. El cálculo, o la expectativa, nunca funcionaron. El 
costo del respaldo fue en todos los casos subestimado. Porque ese costo equivalía a desentenderse de la conducción política del proyecto, y a permitir que se expandiera un sistema perverso de desestructuración y desestabilización de la sociedad en múltiples formas. El costo resultó pues mucho más alto, el beneficio ilusorio.

La gran lección que nos deja la historia política reciente del Perú es que la democracia no es un bien negociable. Esta lección no le es tan fácil de aprender a una sociedad como la peruana, o la latinoamericana, que han vivido experiencias muy dolorosas de inestabilidad social, o que han convivido con democracias corruptas. La tentación del autoritarismo está siempre presente, parece siempre esperanzadora. Lastimosamente, cuando el autoritarismo se instala, como podemos apreciar ahora meridianamente en el caso del Perú, se desata una red de mecanismos de corrupción que terminan por envenenar el tejido social en su conjunto y que atentan contra la tan deseada estabilidad. Con las reglas de juego democráticas no se puede transigir, estas reglas son verdaderamente esenciales para asegurar la estabilidad de cualquier reforma de la sociedad o de la economía. La independencia de los poderes del Estado, la autonomía de las instituciones, esas verdades elementales de la vida democrática, se han ido convirtiendo en lecciones amargas para la sociedad peruana actual. Pero que la democracia no sea un bien negociable significa también que no se puede dejar de participar en ella. La renuncia de los actores sociales en el Perú a intervenir en la concepción y la conducción políticas del proceso, confiando esa tarea al caudillo pacificador, nos ha dejado ahora con "una herencia maldita".

La historia de Vladimiro Montesinos es una historia vergonzosa, pero aleccionadora. La súbita revelación de sus fechorías ha puesto al descubierto la verdadera naturaleza del proyecto autoritario, ha abierto los ojos de sus más obstinados seguidores y ha provocado en el Perú una indignada reacción de protesta moral. Es ella precisamente la que puede librarnos de la tentación del fatalismo o el sarcasmo. Podemos extraer de ella la motivación para emprender una reconstrucción de nuestra democracia, buscando nuevas alianzas políticas si es preciso, y procurando demostrar que esta historia no ha sido vivida en vano. Y convendría que otros, venezolanos, ecuatorianos, colombianos, miraran 
también si no hay aquí tentaciones que evitar. Para forjar nuestras democracias, no nos es suficiente recurrir, como sugiere Rorty, a las viejas tradiciones de nuestra historia. La justificación moral que él busca en los sueños del pasado, nosotros tenemos que encontrarla en las dolorosas lecciones políticas del presente.

\title{
Referências Bibliográficas
}

Rorty, Richard. Forjar nuestro país: El pensamiento de izquierdas en los Estados Unidos del siglo XX. Barcelona: Paidós, 1999.

\begin{abstract}
s
This article aims at explaining the recent history of Peru, in an exercise in which it is possible to extract lessons about the way Latin American democracies have been(or have not been) forged. The text draws a parallel between the ideas developed by Richard Rorty in his recently published book, Forjar nuestro país. El pensamiento de isquierdas en los Estados Unidos del siglo XX. and the events in Fugimori's and Montesinos' Peru. If, according to what Rorty believes, "national pride is for the countries what self esteem is for individuals...", how would it be possible to narrate a history in which there are few motives to be proud of? Trying to escape fatalism and sarcasm, the text tries to show that Montesinos' political course is, symbolically, a summary of the decomposition process of Peruvian democracy. Secondly, the text analyses the movements of the political left wing and deals with the support the regimen received from inside and outside the country, a support that was largely based on the illusion of political stability. Finally, it states, as Rorty does, that in order to forge democracies it is necessary for us to be deeply committed to the defense of the State of Right.
\end{abstract}

Key-words: democracy; peruvian political regimen; Fujimori. 


\section{Resumo}

$\mathrm{O}$ artigo procura explicar a histórica recente do Peru, num exercício em que seja possível extrair lições sobre o modo como vêm sendo (ou não vem sendo) forjadas as democracias latino-americanas. O texto traça um paralelo entre as idéias desenvolvidas por Richard Rorty no livro recentemente publicado, Forjar nuestro país. El pensamiento de izquierdas en los Estados Unidos del siglo XX, e os acontecimentos do Peru de Fujimori e Montesinos. Se, conforme acredita Rorty, "o orgulho nacional é para os países o que a auto-estima é para os indivíduos...", como seria possível narrar uma história na qual aparecem poucos motivos com que se possa orgulhar?. Procurando escapar do fatalismo e do sarcasmo, o texto procura mostrar que a trajetória política de Montesinos é, simbolicamente, um resumo do processo de decomposição da democracia peruana. Em segundo lugar, analisa os movimentos da esquerda política e fala do apoio que o regime recebeu dentro e fora do país, apoio que em grande medida se fundamentou na ilusão da estabilidade política. Finalmente, afirma, tal como Rorty, que para forjar democracias é necessário que nos comprometamos resolutamente com a defesa do Estado de Direito.

Palavias-chave: democracia, regime político peruano; Fujimori. 